\title{
Simulation of underground storage / UM EL-Radhuma \\ Formation-Ratawi field
}

Sameera Mohamed, Hamd-Allah and Hayder Saeed Fukaa

Petroleum Engineering Department, College of Engineering, University of Baghdad

\begin{abstract}
$\underline{\text { Abstract }}$
The aim of this study is to investigate the feasibility of underground storage of gas in Um ElRadhuma formation /Ratawi field. This formation is an aquifer consisting of a high permeable dolomite beds overlain by impermeable anhydrite bed of Rus formation. Interactive petrophysics (IP), Petrel RE and Eclipse 100 softwares were used to conduct a well log interpretation, build a reservoir simulation model and predict the reservoir behavior during storage respectively. A black oil, three dimensional and two phase fluid model has been used. The results showed that the upper part of Um El-Radhuma formation is suitable for underground gas storage, because of the seal of its cap rock and capability of reserving gas in the reservoir. It was found that available volume for storage is 14.3 billion cubic feet with a structural closure of $45 \mathrm{~m}$. the optimum injection rate has been calculated also.
\end{abstract}

\section{$\underline{\text { Introduction }}$}

Natural gas is playing an important role in meeting the world's energy demand because of the clean burning, huge energy that can be supplied by using it. According to the International Energy Agency, in the next 20 years, the average growth rate of global natural gas demand is expected to be over $1.8 \%$ per year [1].

Also, natural gas is known that it is mutable in its demand according to the year seasons, if it is cold or $\operatorname{hot}[2,3]$.

Today in Iraq, large volumes of natural gas are not invested and lost by burning, because the main type of natural gas in Iraq is associated gas and needs high capitals of money to be invested. For example, more than1.5 MMMSCF/d were burned in 2016 which means $1.2 \mathrm{MMMSCF}$ of dry gas, 7500 ton of liquefied gas and 1650 ton of benzene have been lost [4]. Natural gas storage is used to face the expected future peak demand, maintain the balance between supply and demand and to save the noninvested gas from burning and losing [3]. 


\section{Methodology}

During this study, two phase and 3D black oil reservoir simulation model was built to present the aquifer behavior during injection processes. Therefore, Petrel and Eclipse softwares were used to build and simulate the reservoir model. The five main stages that have been conducted during this study were:-

1- Well logs interpretation: during this stage all the data of well logs have been used to find CPI for every well such as porosity, clay volume, water saturation. Well logs interpretation was done by using interactive petrophysics (IP) software. Wells that have been used during for this purpose were RT-3, 6, 7, 8, 9, 10 and 11. Also, fracture pressure has been calculated during this study by using modified Eaton method and interactive petrophysics (IP) software.

2- Building a static geological model: This stage contains all the steps of building the reservoir geological model for Um El-Radhuma formation depending on group of data such as: - well heads, formation units tops, logging data, making a surface contour map of the two formations (Rus and Um El-Radhuma).

3- Building the dynamic reservoir simulation model: Dynamic fluid model is very important because it is used to predict the reservoir behavior with time under any process such as: - production, injection, stimulation and etc.... During this stage, rock physics function and reservoir fluid properties such as capillary pressure, relative permeability data, and two phase fluid properties (injected gas +water) have been entered. The injected gas was from Zubair oil field, well zb-71. Figure 1 to figure 3 shows injected gas properties, relative permeability curve and capillary pressure data for UM EL-Radhuma formation respectively. The initial reservoir and formation water properties were;

Reservoir pressure $=1450$ psi,

Datum depth $=-3000 \mathrm{ft}$.

Gas water contact depth $=-2000 \mathrm{ft}$.

Temperature $=110 \mathrm{~F}^{\circ}$

Water density $=67.549 \mathrm{lb} / \mathrm{ft}^{\wedge} 3$

Solid concentration $=25340 \mathrm{ppm}$

Water Compressibility $=2.4 * 10^{-5} 1 / \mathrm{psi}$

Water formation volume factor $(\mathrm{Bw})=1.0003$ 


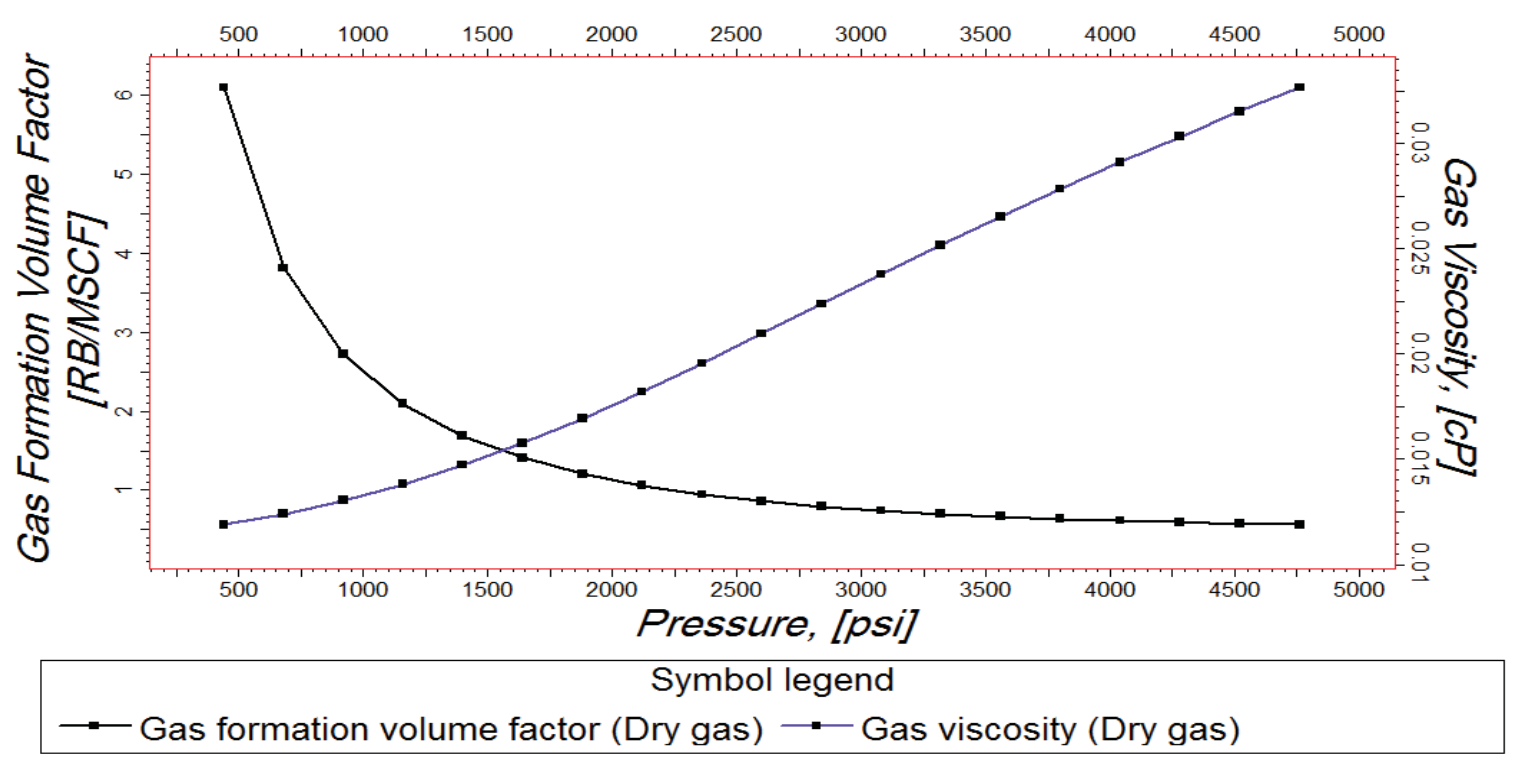

Fig. (1) Injected gas properties. [6]

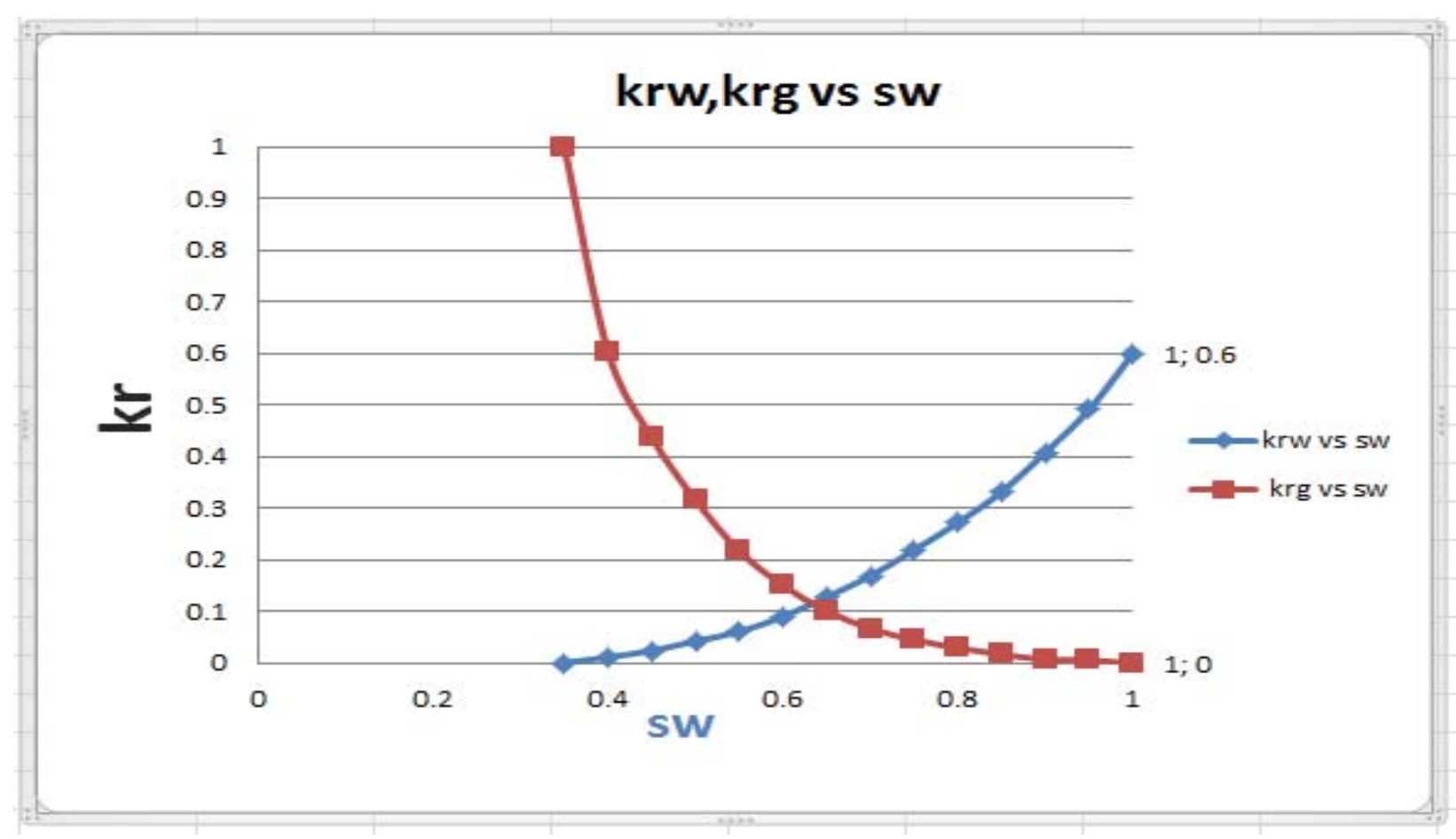

Fig. (2) Relative permeability of gas and water for Um El-Radhuma formation. [5] 


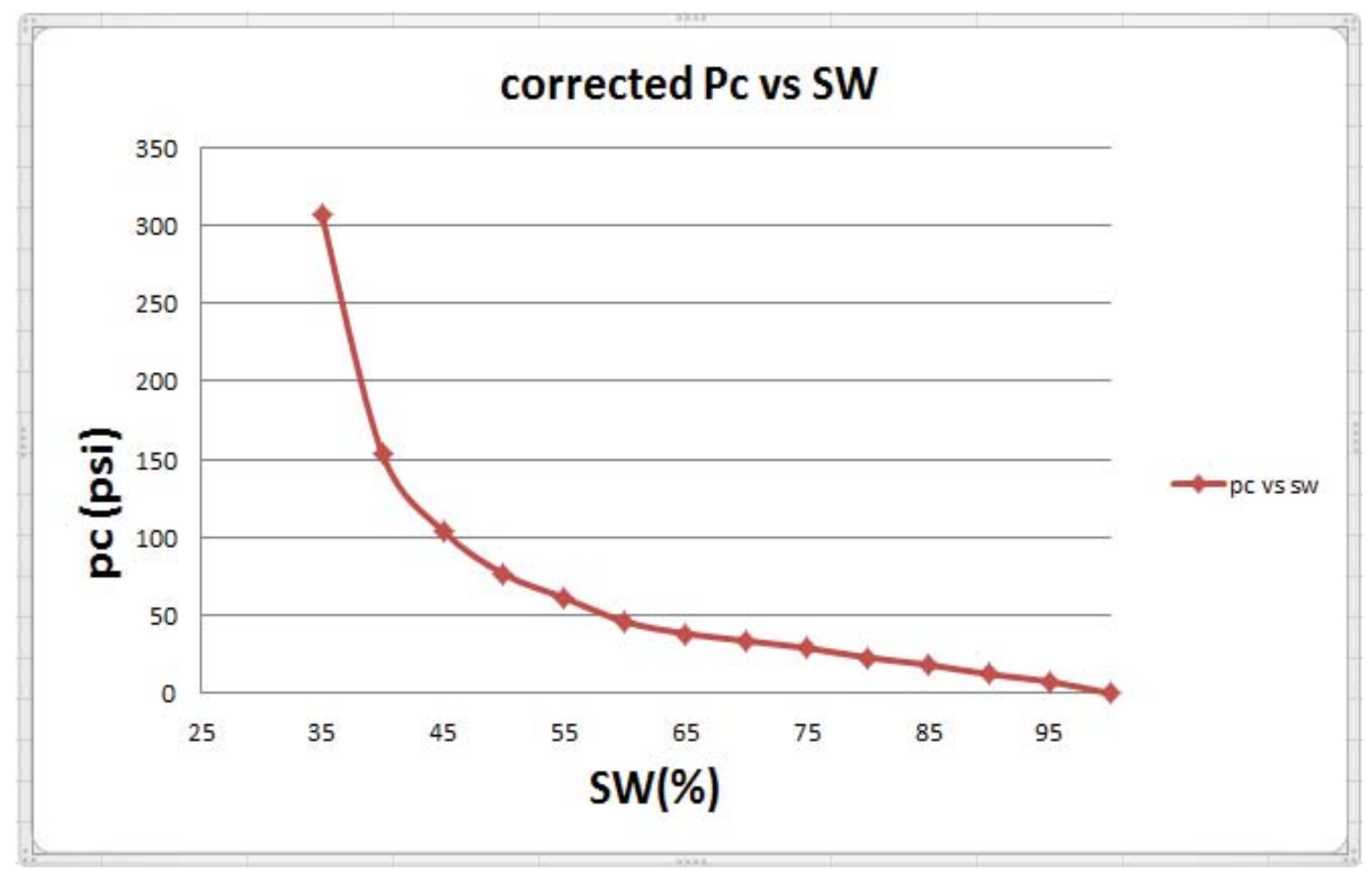

Fig. (3) Capillary pressure curve for UM EL-Radhuma formation. [5]

4- History matching: This stage is very important to verify that the built geological model that was built matches the observed rates and pressure. This is used to prove that the model gives the reasonable prediction result for the future. Therefore, depending on DST tests of well RT-10 for several days, a history matching of the observed data of water production rate and bottom well pressure has been obtained as shown in figure (4) and figure (5) respectively.

5- Predict reservoir behavior during injection: In order to predict reservoir behavior during injection, 9 gas injectors had been added to the model, in addition to wells RT-8 and RT-10. Simulation injection period was for 10 years of injection and the perforation interval was $19 \mathrm{~m}$ with a constant bottom hole pressure (BHP) of 1650 psi which is less than the fracture pressure of 1800 psi. Different flow rates were chosen to find optimum injection rate during this period and to check the cap rock's capability of reserving gas in the reservoir. 


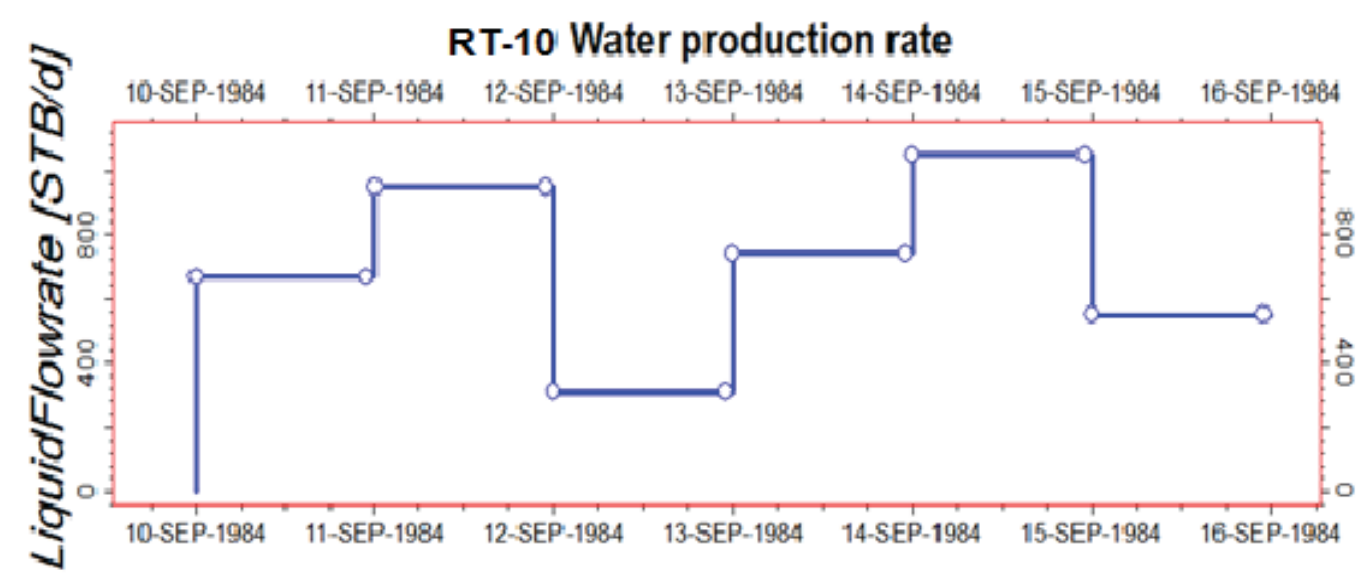

\begin{tabular}{|c|c|}
\hline \multicolumn{2}{|c|}{ Symbal legend } \\
— matching $\quad \circ$ Observed 1 \\
\hline
\end{tabular}

Fig. (4) Water production rate history matching of well RT-10.

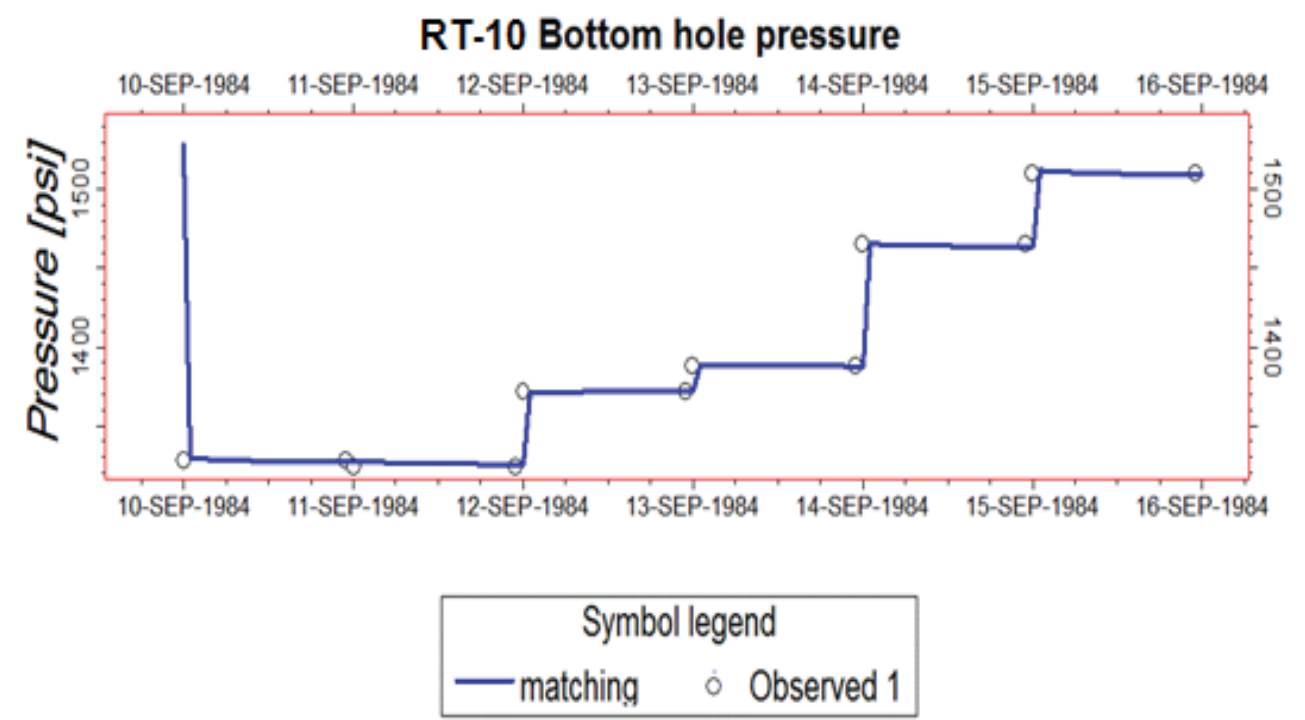

Fig. (5) Bottom hole pressure history matching of well RT-10.

\section{$\underline{\text { Result and discussion }}$}

\section{1- Allowable storage volume:}

According to the volumetric calculation of upper reservoir of Um El-Radhuam formation for the closure area as shown in figure (6) and depending on connate water saturation of 0.35 figure (2) by using equation (1), it is found that allowable storage volume of upper reservoir is equal to 14.3 billion cubic foot.

Allowable storage volume $=$ pore volume $*(1-\mathrm{swc})$ 

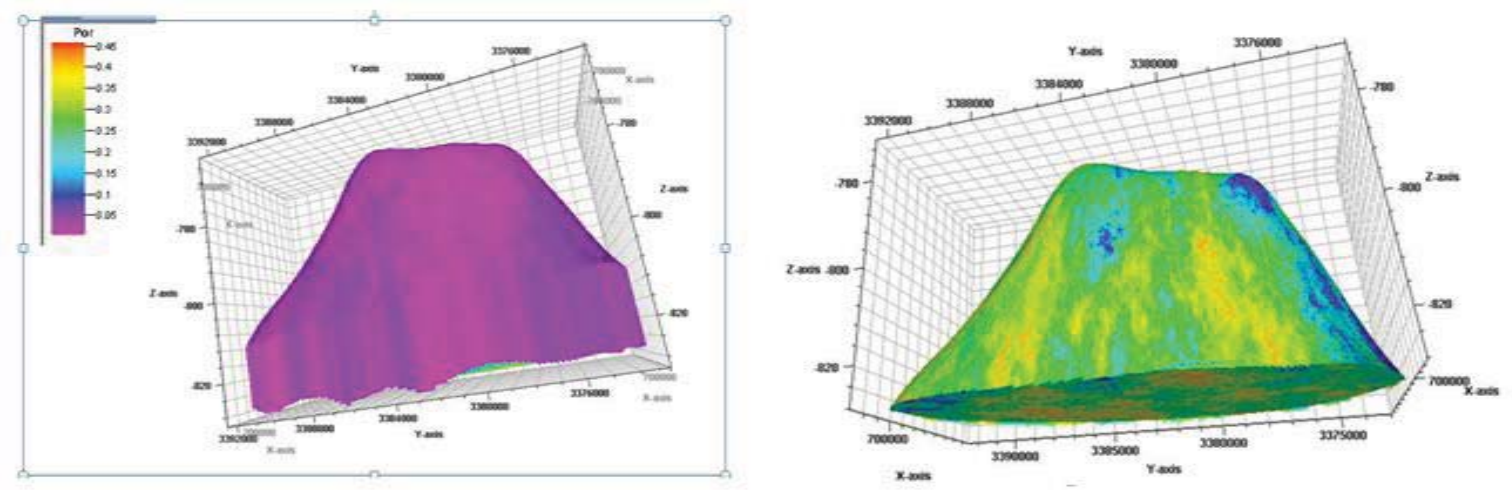

Fig. (6) Porosity distribution of the closure area of upper reservoir and its cap rock.

\section{2- Injection without pressure relief :-}

Pressure relief can be done either by stopping the injection processes for a period or by water withdrawal from the formation bottom. During this stage, several cases with a different injection rates without pressure relief have been conducted in this study to find the optimum injection rate which is achieved when the maximum amount of gas is injected with constant rate and the highest secure bottom hole pressure (BHP) which is 1650 psi.

Therefore, the following cases have been conducted during this stage with a maximum constant bottom hole pressure of 1650 psi:-

- Three cases with a constant injection rates targets of $85 \mathrm{MMSCF} / \mathrm{D}, 65 \mathrm{MMSCF} / \mathrm{D}$ and 51 $\mathrm{MMSCF} / \mathrm{D}$ [case (A, B, C)].

- Injection without injection rate target but, constant BHP of 1650 (case_D).

- Dividing the 10 years simulation period into 5 periods to find optimum injection rate of every period (case_E).

Figure (7) and Figure (8) show the results of gas injection rates, cumulative gas injected and average reservoir pressure for the first three cases $(\mathrm{A}, \mathrm{B}, \mathrm{C})$.

From figure (7), it can be noticed that injection rate target more than $51 \mathrm{MMSCF} / \mathrm{D}$ cannot be sustained. The injection rate continues decreasing after a periods depending on the value of injection rate. This is because of continuous injection leads to an increasing in the formation pressure figure (8) which leads to a decrease in the differential pressure and the last affects injection rate proportionally; therefore, the optimum injection rate of the 10 years injection periods without pressure relief is 51 MMSCF/D. 


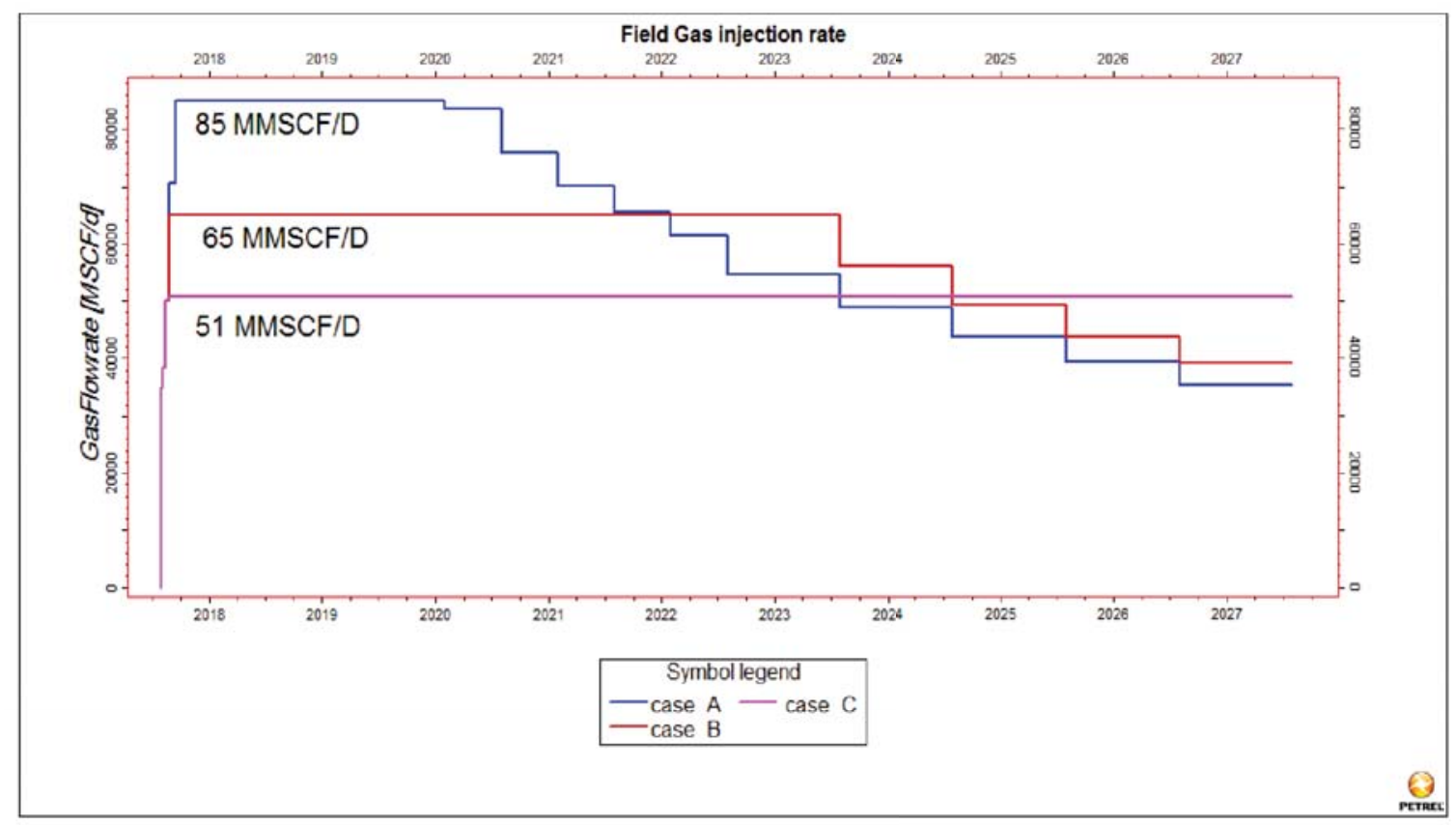

Fig. (7) Gas injection rate of the cases A, B and C during 10 years injection period.

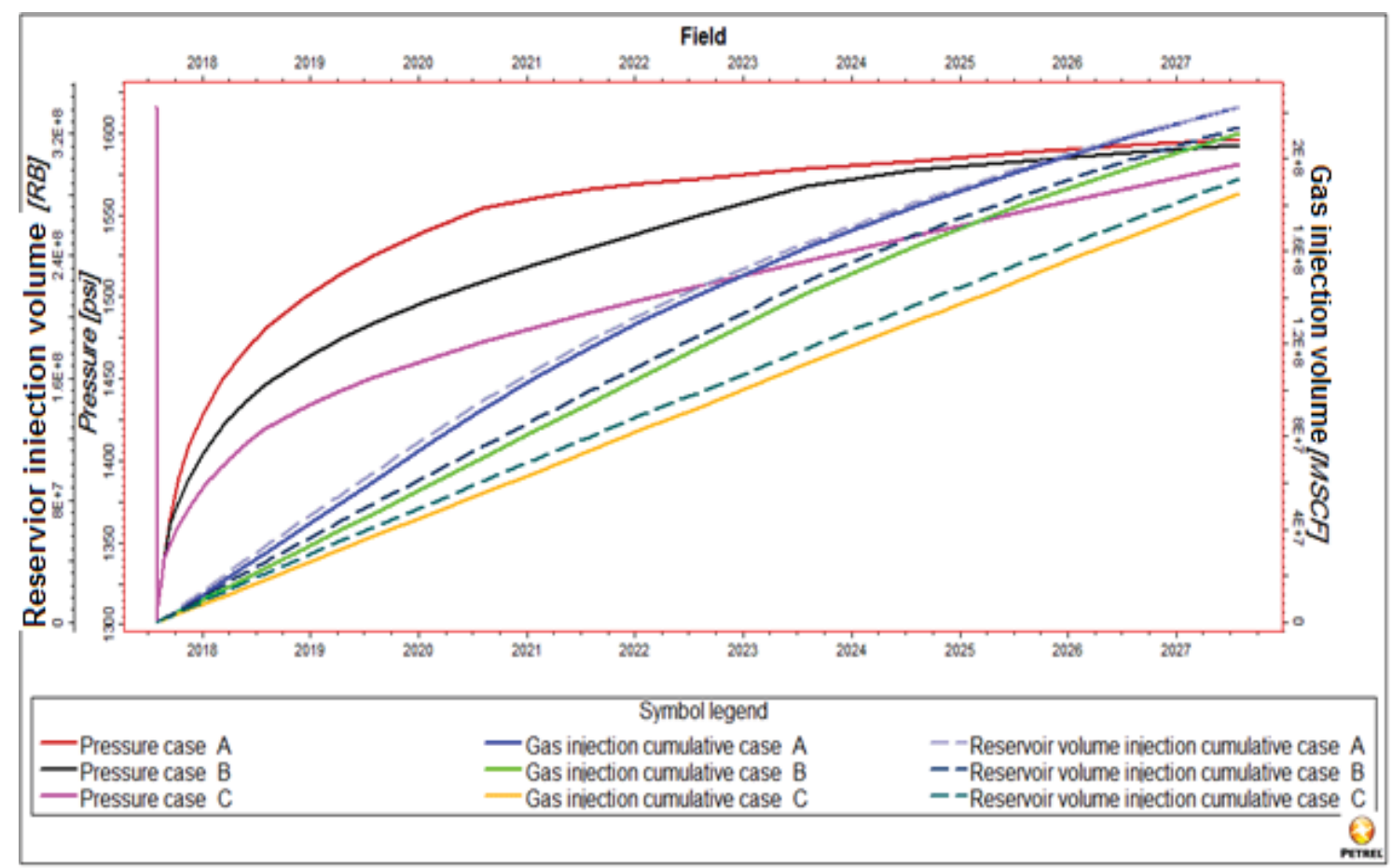

Fig. (8) Average reservoir pressure, reservoir and surface cumulative gas injected of the cases A, $B$ and $C$ during 10 years injection period

The reservoir \& surface cumulative injected gas volume and average formation pressure of the above three cases after 10 years of injection are described in table (1). 
Table (1) Average reservoir pressure, surface and reservoir cumulative gas injected after 10 years of case A, B and C.

\begin{tabular}{|c|c|c|c|c|c|}
\hline $\begin{array}{c}\text { Case } \\
\text { name }\end{array}$ & $\begin{array}{c}\text { Surface } \\
\text { cumulative gas } \\
\text { injected } \\
\text { (MMMSCF) }\end{array}$ & $\begin{array}{c}\text { Reservoir } \\
\text { cumulative gas } \\
\text { injected (RB) }\end{array}$ & $\begin{array}{c}\text { Reservoir } \\
\text { cumulative gas } \\
\text { injected (BCF) }\end{array}$ & $\begin{array}{c}\text { Average } \\
\text { reservoir } \\
\text { pressure } \\
\text { (psi) }\end{array}$ & $\begin{array}{c}\text { Bg } \\
\text { (RB/MSCF) }\end{array}$ \\
\hline A & 222.5 & $338^{*} 10^{6}$ & 1.9 & 1597 & 1.52 \\
\hline B & 210.6 & $324 * 10^{6}$ & 1.81 & 1593 & 1.53 \\
\hline C & 186.1 & $292^{*} 10^{6}$ & 1.64 & 1581 & 1.56 \\
\hline
\end{tabular}

In order to get more gas injection rate and to determine the maximum cumulative gas injected, two cases have been conducted, the first is without injection rate target (case_ D) and the second is with several injection rate periods (case_E).

Figure (9) and Figure (10) show the results of gas injection rates, cumulative gas injected and average reservoir pressure for the two cases.

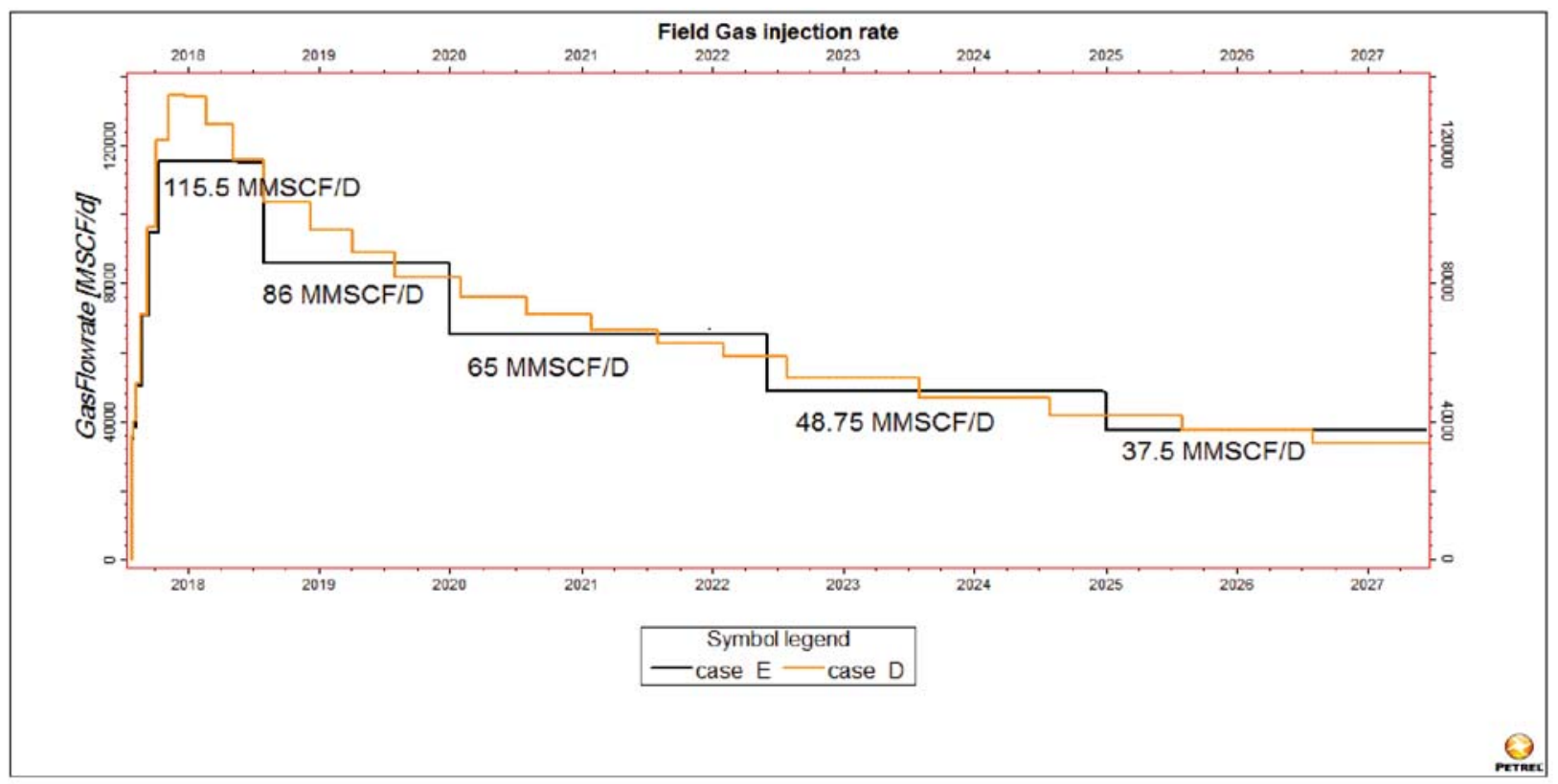

Fig. (9) Gas injection rate of the cases D and $E$ during 10 years injection period. 


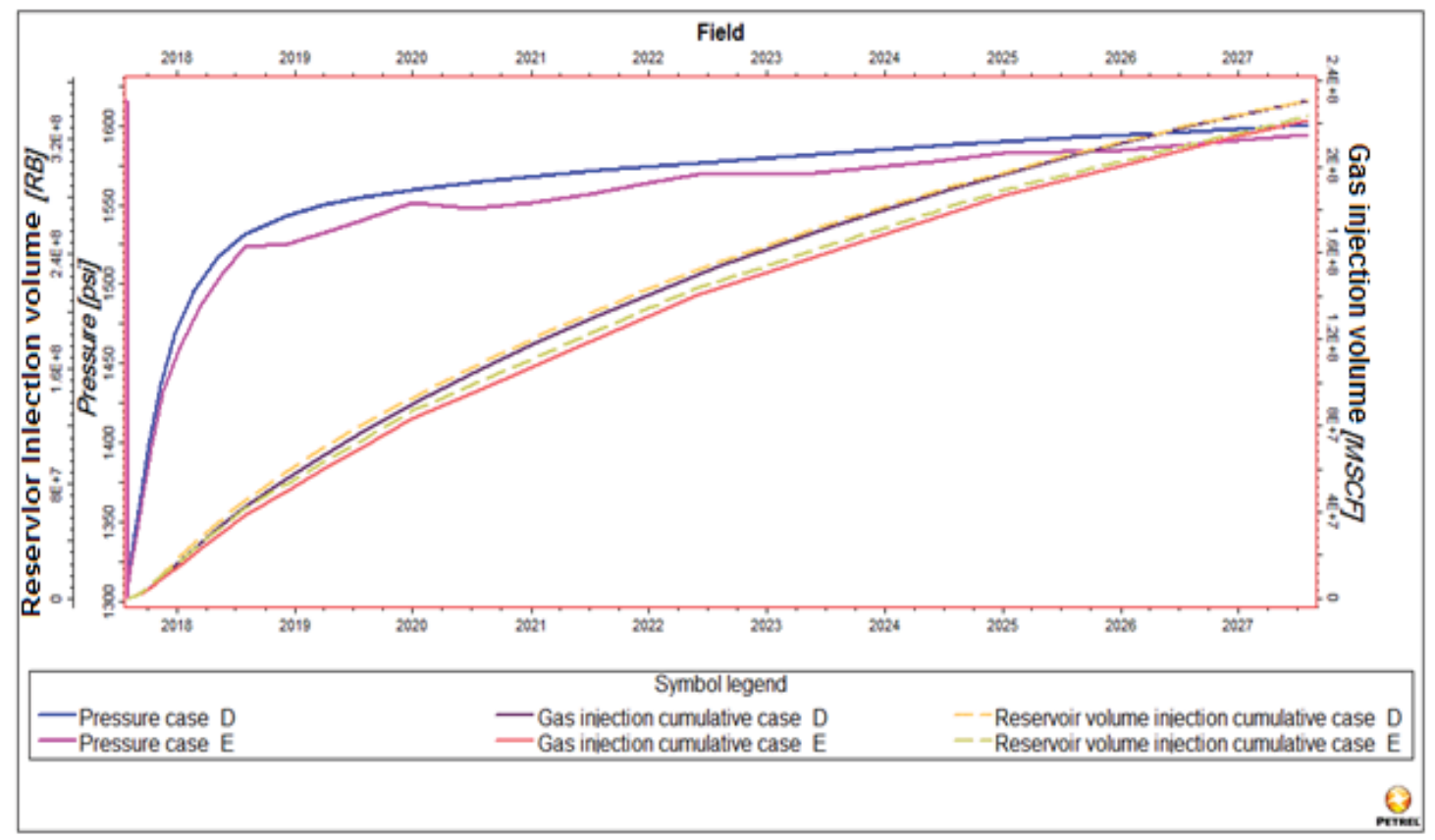

Fig. (10) Average reservoir pressure, reservoir and surface cumulative gas injected of the cases D \& E during 10 years injection period.

From figure (9), it is noticed that injection rate in case D, starts to increase until it reaches to its maximum value, and then decreases because of the increase in formation pressure figure (10) which leads to decrease in injection rate. In order to decrease the formation pressure increment, pressure relief is required which is done either by shut down periods between injection period or by water withdrawal from the bottom of the formation.

Figure (10) showed that the maximum cumulative gas injected for 10 years without pressure relief and at BHP of 1650 psi (case D) was equal to 228.1MMMSCF and from the same figure it could be noticed that cumulative gas injected after 10 years of injection in case $\mathrm{E}$, at different five injection rate targets, is equal to 221.7 MMMSCF.

Table (2) shows the reservoir and surface cumulative injected gas volumes and average formation pressure for the two cases (D and E) after 10 years of injection. 
Table (2) Average reservoir pressure, surface and reservoir cumulative gas injected after 10 years for case $\mathbf{D} \& \mathbf{E}$.

\begin{tabular}{|c|c|c|c|c|c|}
\hline $\begin{array}{c}\text { Case } \\
\text { name }\end{array}$ & $\begin{array}{c}\text { Surface } \\
\text { cumulative gas } \\
\text { injected } \\
\text { (MMMSCF) }\end{array}$ & $\begin{array}{c}\text { Reservoir } \\
\text { cumulative gas } \\
\text { injected (RB) }\end{array}$ & $\begin{array}{c}\text { Reservoir } \\
\text { cumulative gas } \\
\text { injected (BCF) }\end{array}$ & $\begin{array}{c}\text { Bg } \\
\text { (RB/MSCF) }\end{array}$ & $\begin{array}{c}\text { Average } \\
\text { reservoir } \\
\text { pressure } \\
\text { (psi) }\end{array}$ \\
\hline D & 230.9 & $338^{*} 10^{6}$ & 1.9 & 1.46 & 1600 \\
\hline E & 221.7 & $347.5^{*} 10^{6}$ & 1.95 & 1.56 & 1595 \\
\hline
\end{tabular}

From the comparison between figure (7) and figure (9), it can be noticed that discretization the injection period into several periods with several injection rate targets leads to an increase in the optimum injection rate, which leads to an increase in the cumulative gas injected figure (8 \& 10). Therefore, increasing the injection periods leads to an increase in optimum injection rate target.

Optimum injection rate of every period during case E are described in table (3) which is the injection rate target of every period as shown in figure (9).

Table (3) Optimum injection rates for every period in case $\mathbf{E}$ during 10 years.

\begin{tabular}{|c|c|c|c|c|c|c|}
\hline Period & $\begin{array}{l}01 / 08 / 2017- \\
31 / 07 / 2018\end{array}$ & $\begin{array}{l}01 / 08 / 2018- \\
31 / 12 / 2019\end{array}$ & $\begin{array}{l}01 / 01 / 2020- \\
31 / 05 / 2022\end{array}$ & $\begin{array}{l}01 / 06 / 2022- \\
31 / 12 / 2024\end{array}$ & $\begin{array}{l}\text { 01/01/2025- } \\
31 / 07 / 2027\end{array}$ & $\begin{array}{l}\text { Cumm. } \\
\text { mmmscf }\end{array}$ \\
\hline $\begin{array}{l}\text { Injection rate } \\
(\mathrm{MMSCF} / \mathrm{D})\end{array}$ & 115.5 & 85 & 65 & 48.75 & 37.5 & 221.7 \\
\hline
\end{tabular}

\section{Conclusions}

1- Upper reservoir of Um El-Radhuma formation in Rtawi field is suitable for underground gas storage, because of its cap rock capability to reserve gas.

2- Present allowable reservoir storage volume of upper reservoir of Um El-Radhuma formation is 14.3 billion cubic foot.

3- Optimum injection rate of 10 years without pressure relief is $51 \mathrm{MMSCF} / \mathrm{D}$.

4- Discretization of injection period into several periods leads to an increase in the optimum injection rate and cumulative injected gas. 


\section{References}

1. Michael J. Economides and Xiuli Wang, "A Modern Approach to Optimizing Underground Natural Gas Storage", SPE (2013) 166080.

2. C. I. C. Anyadiegwn, "Development of depleted oil reservoirs for simultaneous gas injection for underground natural gas storage and enhanced oil recovery in Nigeria", SPE (2016) 184270.

3. IEA: International Energy Agency World Energy Outlook, 2016.

4. Asri Musa," Iraq as producer and exporter of gas", presentation, March- 2016.

5. Core analysis report of wells (RT-8, RT-9, RT-10, RT-11), Ministry of Oil-Reservoirs \& Fields Development Directorate.

6. Gas properties of Zubair field /well ZB-71, Basrah oil Company. 